
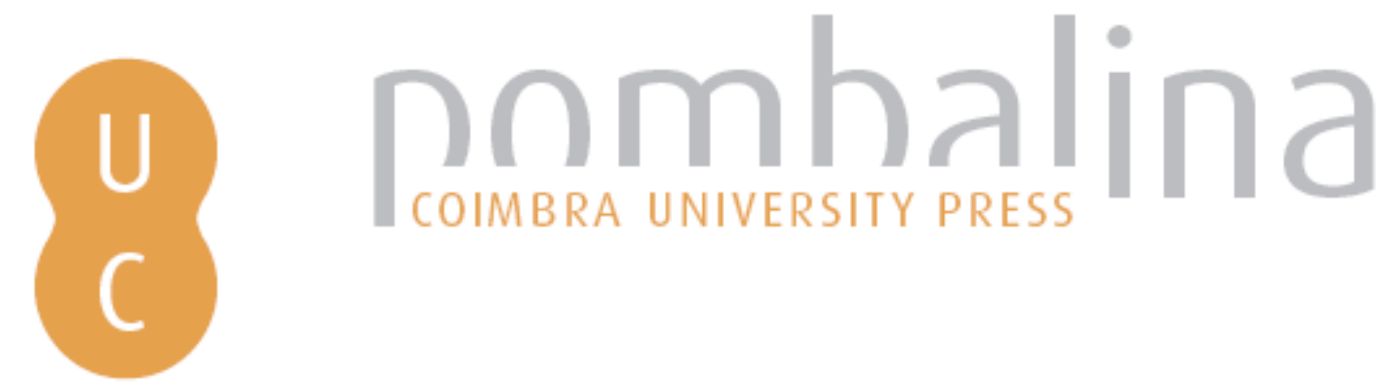

\title{
A bacia hidrográfica do rio Arunca: factores condicionantes e cartografia dos processos de cheia/inundação
}

Autor(es): $\quad$ Santos, Pedro; Andrade, Ana Isabel; Tavares, Alexandre

Publicado por: Imprensa da Universidade de Coimbra

URL

persistente: URI:http://hdl.handle.net/10316.2/31215

DOI: $\quad$ DOI:http://dx.doi.org/10.14195/978-989-26-0244-8_99

Accessed : $\quad$ 26-Apr-2023 11:48:10

A navegação consulta e descarregamento dos títulos inseridos nas Bibliotecas Digitais UC Digitalis, UC Pombalina e UC Impactum, pressupõem a aceitação plena e sem reservas dos Termos e Condições de Uso destas Bibliotecas Digitais, disponíveis em https://digitalis.uc.pt/pt-pt/termos.

Conforme exposto nos referidos Termos e Condições de Uso, o descarregamento de títulos de acesso restrito requer uma licença válida de autorização devendo o utilizador aceder ao(s) documento(s) a partir de um endereço de IP da instituição detentora da supramencionada licença.

Ao utilizador é apenas permitido o descarregamento para uso pessoal, pelo que o emprego do(s) título(s) descarregado(s) para outro fim, designadamente comercial, carece de autorização do respetivo autor ou editor da obra.

Na medida em que todas as obras da UC Digitalis se encontram protegidas pelo Código do Direito de Autor e Direitos Conexos e demais legislação aplicável, toda a cópia, parcial ou total, deste documento, nos casos em que é legalmente admitida, deverá conter ou fazer-se acompanhar por este aviso.

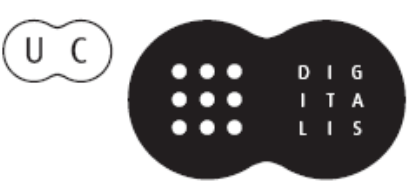




\section{TRUNFOS DE UMA}

\section{EOGRAFIA ACIVA}

\section{DESENVOLVIMENTO LOCAL,}

AMBIENTE,

ORDENAMENTO

E TECNOLOGIA

Norberto Santos

Lúcio Cunha

COORDENAÇÃO 
Pedro Santos ${ }^{1}$, Ana Isabel Andrade ${ }^{2}$, Alexandre Tavares ${ }^{3}$

${ }^{1}$ Centro de Geofisica, Universidade de Coimbra

${ }^{2}$ Centro de Geofísica, Dep. de Ciências da Terra, Univ. de Coimbra

${ }^{3}$ Centro de Estudos Sociais, Dep. de Ciências da Terra, Univ. de Coimbra

\section{A BACIA HIDROGRÁFICA DO RIO ARUNCA. \\ FACTORES CONDICIONANTES E CARTOGRAFIA DOS PROCESSOS DE CHEIA/INUNDAÇÃO}

\section{INTRODUÇÃO}

As cheias/inundaçóes são processos naturais causadores de impactes significativos na sociedade, na economia, no património e no ambiente. A definição de áreas inundáveis, a partir da qual se procede à avaliação do risco, constitui uma prioridade ao nível europeu, expressa na Directiva «Inundaçóes» (Directiva 2007/60/CE de 23 de Outubro). A importância desta avaliação para o Ordenamento do Território é evidente - e inicia-se com a cartografia da perigosidade - porquanto a dinâmica na transformação no uso do solo é hoje muito forte, originando a que áreas que actualmente não apresentam risco possam num futuro próximo - ou à escala temporal de vigência de um Instrumento de Gestão Territorial - apresentar.

$\mathrm{Na}$ bacia hidrográfica do rio Arunca (BHA) ocorrem episódios de cheias/inundaçóes. Os dados históricos referentes a estes eventos são relativamente escassos, não obstante os inúmeros episódios vivenciados e recordados pela população. Algumas cheias que afectam o curso inferior do rio Arunca evoluem de jusante para montante, tendo por origem as cheias que ocorrem no rio Mondego. O rio Arunca tem uma dinâmica hidrológica própria ocasionando inundaçóes de consequências significativas, como por exemplo a ocorrida no século XVIII, descrita no livro de óbitos da freguesia de Soure (SOARES, 1971). Mais recentemente estão documentadas as inundaçóes do ano de 2001, afectando a planície aluvial a jusante de Pombal, e as cheias do ano de 2006.

O presente artigo refere-se a um estudo realizado no âmbito de uma tese de mestrado, no qual se produziu cartografia de áreas inundáveis por dois métodos de análise. Procura-se assim conhecer as condiçóes de escoamento e as áreas inundáveis para um período de retorno de 100 anos, através da utilização de um método de reconstituição paleo-hidrogeomorfológica. A análise permite ainda reconstituir as condiçóes de fluxo e inundação actuais, de acordo com as alteraçóes antrópicas recentes no canal e margens. Efectua-se um estudo comparativo entre as áreas obtidas para a inundação histórica e para a inundação actual, sendo a validação dos resultados realizada com aplicação de um método hidrológico-hidráulico. 


\section{A BACIA HIDROGRÁFICA DO RIO ARUNCA}

A bacia hidrográfica do rio Arunca (Fig. 1) tem uma área de $550 \mathrm{~km}^{2}$ e pertence à bacia hidrográfica do rio Mondego, situando-se na unidade do Baixo Mondego, «a porção mais ocidental» da bacia deste rio (ALMEIDA et al., 1990). O curso de água principal tem um comprimento de 55,76 km, sendo o maior afluente do rio Mondego na Orla Mesocenozóica Ocidental. As principais unidades morfo-estruturais existentes na área da bacia são, segundo a terminologia de ALMEIDA et al. (1990), as serras e planaltos calcários, as colinas gresosas (incluindo a sub-unidade denominada «superfície plio-calabriana»), o diapiro de Soure e a planície aluvial.

Figura 1 - Enquadramento geográfico da bacia hidrográfica do rio Arunca

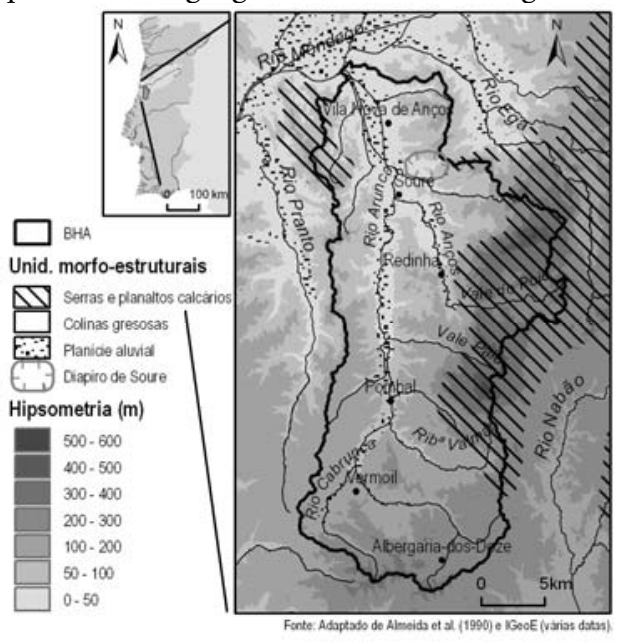

As condiçôes morfológicas da bacia, nomeadamente a platitude aluvionar e os estrangulamentos estruturais, as características hidrológicas e hidrogeológicas dos materiais sedimentares, a ocupação e transformação antrópica das margens condicionam a severidade das cheias e inundaçóes que ocorrem na bacia.

A precipitação média ponderada anual da bacia hidrográfica do rio Arunca foi calculada em $965 \mathrm{~mm}$, sendo mais elevada nos sectores de maior altitude do maciço calcário, com valores médios de precipitação anual no período 1978/79 - 2005/06 superiores a $1200 \mathrm{~mm}$ (1235 $\mathrm{mm}$ na estação de Degracias). Os valores anuais médios mais reduzidos ocorrem no sector setentrional e ocidental da bacia, correspondendo às áreas de menor altitude, verificando-se valores entre 800 e $900 \mathrm{~mm}$. Os valores de precipitação da Tabela 1 correspondem aos valores diários máximos esperados, de acordo com as séries de dados disponíveis.

A ocorrência destes eventos extremos na BHA relaciona-se fortemente com o factor orográfico e assume elevada relevância no estudo das cheias porque os episódios de precipitação intensa de curta duração estão na génese de cheias rápidas, um tipo de cheia frequente na bacia do rio Arunca. $\mathrm{O}$ valor máximo de precipitação registado em 24 horas ocorreu em Albergaria-dos-Doze no dia 30 de Abril de 1988 (216,8 mm). Trata-se de um 
valor excepcional que ocorre infelizmente na estação udográfica com o menor número de observaçóes, facto que impossibilita uma estimativa precisa do período de retorno. $\mathrm{O}$ valor máximo registado em Pombal $(104,8 \mathrm{~mm})$ ocorreu recentemente, a 25 de Outubro de 2006. De acordo com INAG (2007), entre as 00:30 e as 01:00 do dia 25, precipitaram em Pombal cerca de $40 \mathrm{~mm}$ enquanto em Soure esse valor foi de 17,5 mm. Para as duraçôes de 6 horas verificaram-se 86,6 mm em Pombal e 42,4 mm em Soure, demonstrando o carácter extremamente localizado deste tipo de processos meteorológicos.

Tabela 1 - Precipitação máxima diária anual observada e esperada (mm).

\begin{tabular}{lcc|ccccccc}
\hline \multirow{2}{*}{$\begin{array}{l}\text { Estaçáo } \\
\text { Udográfica }\end{array}$} & \multicolumn{6}{c|}{ Obs. } & \multicolumn{7}{c}{ Período de Retorno (T) } \\
\cline { 2 - 11 } & $\begin{array}{c}\text { N.o } \\
\text { anos }\end{array}$ & $\begin{array}{l}\text { Valor } \\
\text { Max. }\end{array}$ & 2 & 5 & 10 & 25 & 50 & 100 & 500 \\
\hline Soure & 69 & 120,0 & 44,9 & 58,4 & 67,3 & 78,6 & 86,9 & 95,2 & 114,3 \\
\hline Degracias & 28 & 135,2 & 54,2 & 73,5 & 86,4 & 102,6 & 114,6 & 126,5 & 154,1 \\
\hline Pombal & 64 & 104,8 & 48,6 & 62,9 & 72,4 & 84,4 & 93,3 & 102,2 & 122,6 \\
\hline Alb.-dos-Doze & 17 & 216,8 & 58,1 & 95,0 & 119,4 & 150,2 & 173,1 & 195,8 & 248,2 \\
\hline
\end{tabular}

$\mathrm{Na}$ Fig. 2-A ilustra-se a hierarquia da rede hidrográfica segundo a metodologia de Horton, estando representados os cursos com hierarquia fluvial superior ou igual a 5 . A linha de água com maior desnível (Fig. 2-B e 2-C) é o rio Arunca, apresentando contudo um fraco declive - em virtude de grande parte do seu percurso se fazer sobre a planície alu-vial - e poucas quebras de declive.

Figura 2 - Hierarquia fluvial segundo o método de Horton na BHA (A). Perfil longitudinal dos afluentes da margem direita (B) e da margem esquerda (C) do rio Arunca.
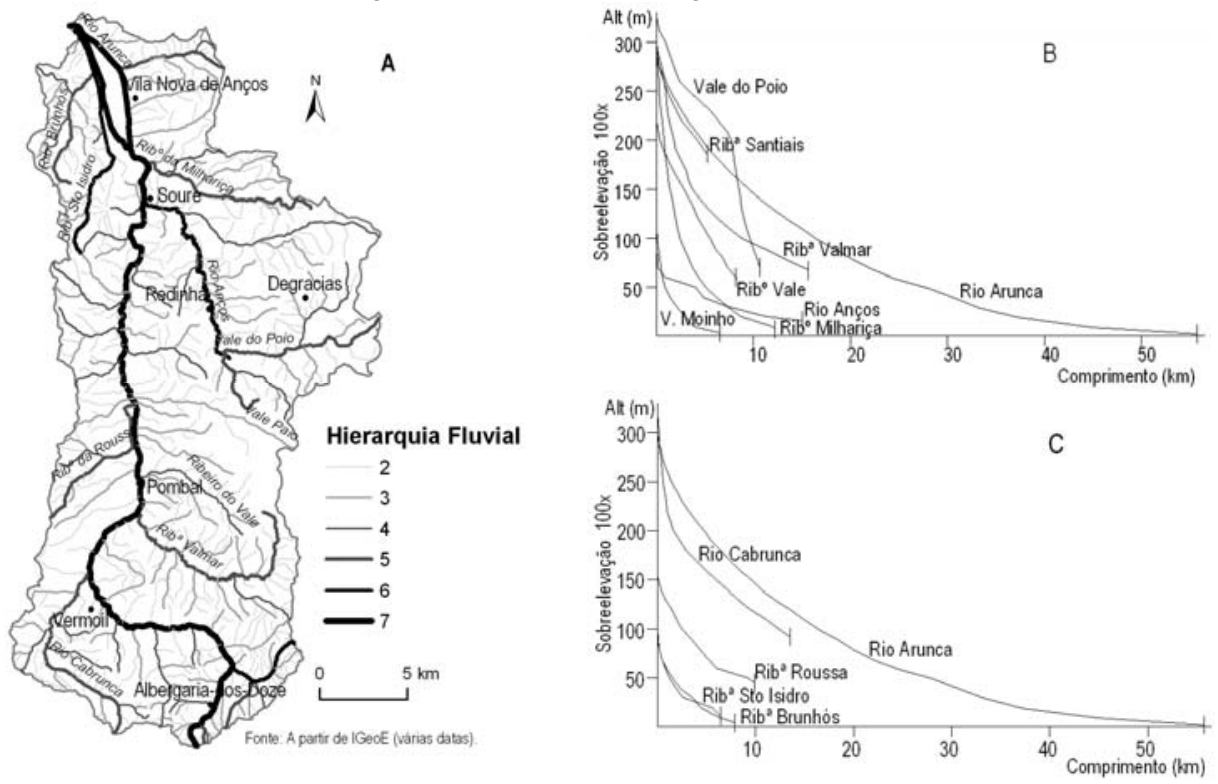
A Fig. 2-C permite observar que os afluentes da margem esquerda - aqueles que entalham os materiais friáveis da bacia terciária - apresentam um declive mais suave no seu curso superior. O Vale do Poio, afluente do rio Anços, é o curso de água de perfil longitudinal mais irregular, chegando este a apresentar-se convexo no seu sector intermédio. Nesta linha de água observa-se um forte declive na área onde o canhão cársico corta a escarpa de falha - o perfil longitudinal passa da cota dos $200 \mathrm{~m}$ aos $120 \mathrm{em}$ apenas $1,2 \mathrm{~km}$ de extensão, a que corresponde um declive de 6,7\%. A Fig. 2-A evidencia ainda a significativa quebra de declive que se verifica no rio Anços entre os 50 e os 40 metros de altitude, na localidade de Redinha.

Tabela 2 - Quadro-resumo dos parâmetros fisiométricos e de drenagem da BHA.

\begin{tabular}{llll}
\hline Coef. de compacidade & 1,672 & Declividade media $(\%)$ & 10,97 \\
\hline Factor de forma & 0,177 & Densid. drenagem $\left(\mathrm{km} / \mathrm{km}^{2}\right)$ & 3,41 \\
\hline Altitude média $(\mathrm{m})$ & 151,0 & Densidade hídrica & 4,7 \\
\hline Altura média $(\mathrm{m})$ & 147,0 & Coef. de torrencialidade & 15,9 \\
\hline Percurso médio escoamento $(\mathrm{km})$ & 0,073 & & \\
\hline
\end{tabular}

A densidade de drenagem $\left(D_{d}\right)$ na BHA é de $3,41 \mathrm{~km} / \mathrm{km}^{2}$ (Tabela 2). Cerca de $53 \%$ da área da bacia $\left(294 \mathrm{~km}^{2}\right)$ tem densidade de drenagem entre 0,5 e $3,5 \mathrm{~km} / \mathrm{km}^{2}$. A classe de $D_{d}$ inferior a $0,5 \mathrm{~km} / \mathrm{km}^{2}$ ocorre em poucos sectores da bacia - na foz do rio Arunca e no topo da Serra do Sicó relacionada com a elevada permeabilidade das rochas cársicas. $\mathrm{O}$ coeficiente de torrencialidade $\left(C_{t}\right)$ obtido para a BHA é de 15,9 , o que no contexto português permite concluir que se trata de um valor mediano. $\mathrm{O}$ padrão de drenagem dominante na BHA é o padrão dendrítico típico. Assim, do ponto de vista morfológico e hidráulico a bacia do Rio Arunca pode ser representada por três sectores distintos: um superior a montante de Pombal, um sector intermédio e um sector inferior a jusante de Soure, com o alargamento do plaino aluvial até à confluência com rio Mondego.

Tabela 3 - Caudais de ponta de cheia apresentados no PBH Mondego.

\begin{tabular}{ccc}
\hline \multirow{2}{*}{$\begin{array}{c}\text { Período de retorno } \\
(\text { anos })\end{array}$} & \multicolumn{2}{c}{ Caudal $\left(\mathrm{m}^{3} / \mathrm{s}\right)$} \\
\cline { 2 - 3 } & $\begin{array}{c}\text { Arunca-Soure } \\
\left(\mathrm{A}=436 \mathrm{~km}^{2}\right)\end{array}$ & $\begin{array}{c}\text { Arunca-Pombal } \\
\left(\mathrm{A}=177 \mathrm{~km}^{2}\right)\end{array}$ \\
\hline 5 & 327 & 169 \\
\hline 10 & 410 & 212 \\
\hline 25 & 518 & 268 \\
\hline 50 & 602 & 311 \\
\hline 100 & 685 & 354 \\
\hline 500 & 882 & 455 \\
\hline 1000 & 967 & 498 \\
\hline
\end{tabular}

No Plano de Bacia Hidrográfica (PBH) do Mondego (INAG, 2002) são apresentados valores estimados para os caudais de ponta de cheia para diferentes períodos de retorno recorrendo ao programa de modelação hidrológica HEC-1, segundo a metodologia do Soil Conservation Service (SCS) (Tabela 3). O maior valor de caudal máximo instantâneo registado na estação hidrométrica de Ponte Mocate, situada cerca de $3 \mathrm{~km}$ a jusante de Soure, 
entre $1972 / 73$ e $1990 / 91$ é de $552,32 \mathrm{~m}^{3} / \mathrm{s}$ no ano hidrológico 1981/82 (DGADR, 1986), ao qual corresponde um período de retorno entre 25 e 50 anos (cf. Tabela 3). No âmbito deste trabalho estimou-se, recorrendo ao método do SCS, um caudal centenário de $334,54 \mathrm{~m}^{3} / \mathrm{s}$ para o rio Arunca em Pombal e de $686,65 \mathrm{~m}^{3} / \mathrm{s}$ em Soure, valores próximos aos apresentados no PBH Mondego.

A análise do uso e ocupação do solo na bacia faz ressaltar a elevada expressão dos espaços agrícolas com culturas anuais (42,9\% da área da bacia); os espaços florestais $(33,9 \%)$; os espaços arbustivos/herbáceos ou degradados (16,8\%); os espaços urbanos, industriais/ /comerciais ou com infra-estruturas $(2,5 \%)$ e os espaços agrícolas de regadio ou de zonas húmidas (3,9\%). A distribuição do uso e ocupação do solo é contudo diferenciada na bacia, merecendo saliência a localização proximal ao curso de água principal dos aglomerados de Pombal e Soure.

\section{METODOLOGIA DE CARTOGRAFIA DAS ÁREAS INUNDÁVEIS}

A cartografia de áreas inundáveis correspondente às inundaçóes histórica e actual na BHA foi elaborada por aplicação do método de reconstituição paleo-hidrogeomorfológica. Do trabalho realizado resultou igualmente a identificação de pontos críticos de escoamento (PCE). Os dois tipos de áreas inundáveis correspondem a ocorrências distintas: inundação actual entendida como a inundação que resulta das condiçóes de fluxo e de modelaçáo morfo-hidráulica actuais, representando as ocorrências verificadas e vivenciadas nos últimos 25 anos; inundação histórica, testemunhando os processos de fluxo máximos reportados para a bacia e equivale à inundação cujos limites máximos de área inundada estão na memória das pessoas (porque a viveram ou porque dela ouviram falar) e que foram simultaneamente comprovados por registos paleo-hidrogeomorfológicos. Assume-se, assim, que a inundação histórica terá um período de retorno próximo dos 100 anos, reconhecendo-se a dificuldade em atribuir o período de retorno.

O método aplicado combina técnicas dos métodos histórico, geológico e geomorfológico tal como definidos em MASSON et al. (1996), BALlAis et al. (2005) e DíEZ-HERRERO et al. (2008), tendo-se realizado levantamentos de reconstituição paleo-hidrogeomorfológica a partir da análise de fotografias aéreas de falsa cor na escala 1/15000, análise de topografia a grande escala, com especial atenção às formas de deposição e erosão, e o estudo de cor, granulometria e maturidade dos depósitos fluviais enquadrantes. Associou-se à análise o levantamento de registos epigráficos de níveis da água observáveis em inúmeros elementos antropicos e naturais (marcas com indicação, ou não, da data de ocorrência em pilares de pontes, muros e habitaçóes, entre outros). Complementou-se a análise com uma inquirição à população sobre as vivências relacionadas com níveis elevados de caudal e área inundada. A recolha de dados históricos obtidos através de fontes documentais e entrevistas à população é apontada como um recurso fundamental na definição de áreas inundáveis (LASTRA et al., 2008). A aplicação do questionário decorreu em 2007, tendo sido administrado de jusante para montante. No trabalho de inquirição realizado efectuaram-se 119 registos dos quais se obtiveram dados relativos à extensão das áreas inundáveis, datas de cheias/inundaçôes, perdas e danos associados, profundidade da coluna de água e tempo de permanência.

De modo a poder comparar os resultados obtidos e validar a cartografia de áreas inundáveis obtidas, procedeu-se à aplicação do método hidrológico-hidráulico recorrendo a mo- 
delação do caudal em regime constante usando o programa de modelação unidimensional HEC-RAS, versão 3.1.3, concebido pelo Hydrologic Engineering Center do United States Army Corps of Engineers (USACE), onde a sigla RAS significa River Analysis System (HEC, 2002). Este método foi aplicado a quatro secçóes do rio Arunca: Secção A (perto de Vermoil), Secção B (na cidade de Pombal), Secção C (na vila de Soure) e Secção D (entre Ponte Mocate e Vila Nova de Anços). A selecçáo dos locais procurou representar os três sectores da bacia e simultaneamente o enquadramento rural e urbano. A modelaçáo hidráulica foi realizada com o objectivo de definir as áreas inundáveis para um período de retorno de 100 anos, possibilitando a comparação com a reconstituição paleo-hidrogeomorfológica da inundação histórica e as condiçôes da inundação actual. A principal condicionante na escolha das secçóes a modelar consistiu na disponibilidade de cartografia de grande escala, preferencialmente igual ou superior a 1:10.000. No caso concreto utilizaram-se dados altimétricos produzidos à escala 1:2000 no concelho de Pombal e 1:10.000 no concelho de Soure.

\section{Resultados}

Na Fig. 3-A aparecem representadas as áreas cartografadas na BHA para a inundação histórica, para a qual se assume um período de retorno de 100 anos, assim como as áreas que estão associadas às condiçóes actuais de inundação na bacia. Na Fig. 3-B é apresentada a localizaçáo dos pontos críticos de escoamento superficial (PCE), num total de 253, e que representam situaçóes em que se observam obstáculos ao escoamento fluvial e/ou locais afectados pelo escoamento existentes a montante ou a jusante do local (ver também Fig. 4).

Figura 3 - Representação da cheia histórica e da cheia actual do rio Arunca e tributários (A), e dos pontos críticos de escoamento superficial (B).
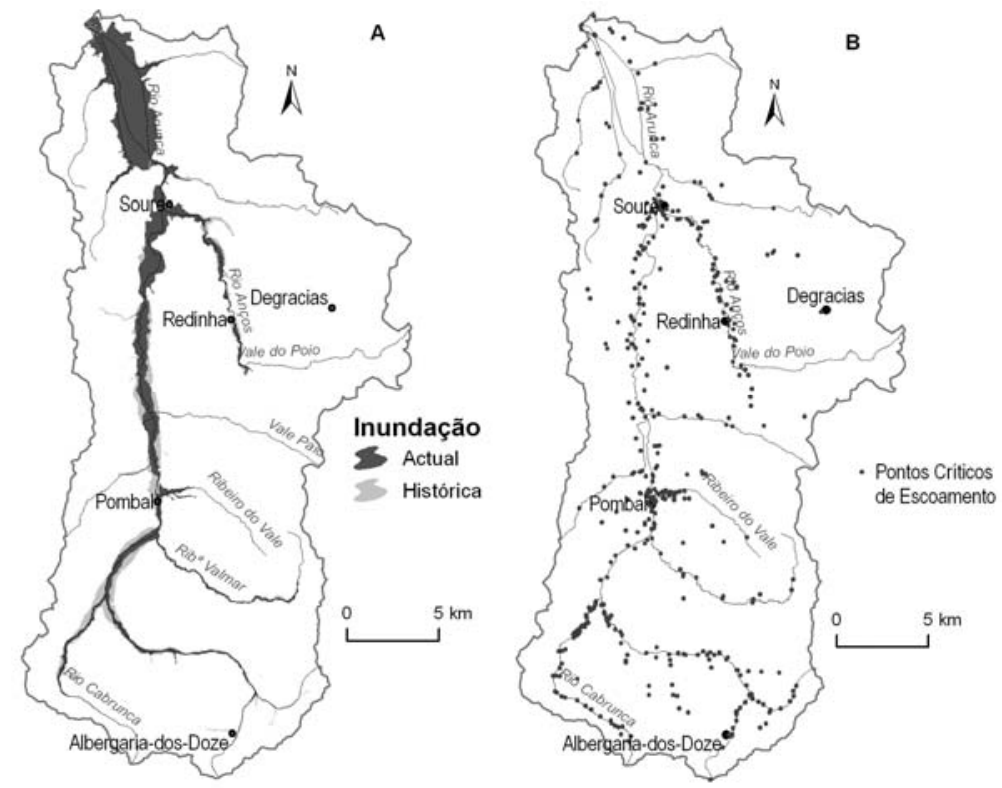
Figura 4 - Cartografia das áreas inundáveis e dos pontos críticos de escoamento em alguns locais da BHA.

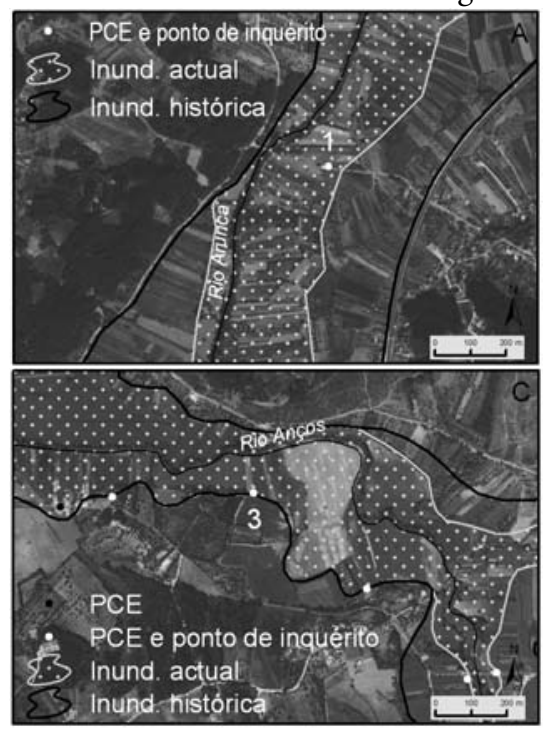

Local: Valdeira $(5 \mathrm{~km}$ a montante de

Pombal) - Rio Arunca.

Altura da água no ponto 1: $0,40 \mathrm{~m}$.

Altura média da água no leito maior: entre 0,3 e $1 \mathrm{~m}$.

Bens afectados: Via rodoviária e áreas agrícolas.

Local: Paleão - Rio Anços.

Altura da água no ponto 3: $<0,30 \mathrm{~m}$.

Altura média da água no leito maior: entre 0,3 e $1 \mathrm{~m}$.

Bens afectados: Caminhos; áreas agrícolas, habitaçôes unifamiliares.

Nestes pontos críticos os principais elementos expostos são vias de comunicação (pontes e estradas pavimentadas ou em terra batida) e construçôes que são. A maior concentração de PCE ocorre nas áreas de Pombal e Soure, salientando-se ainda os pontos localizados ao longo dos cursos de água de menor hierarquia fluvial, distribuídos pelos vários sectores da bacia.

$\mathrm{Na}$ Tabela 4 aparecem representados os valores das áreas inundáveis nos três sectores distintos, do ponto de vista morfológico e hidráulico, da bacia do Rio Arunca, assim como a distribuição dos pontos críticos de escoamento. A análise dos resultados salienta uma área inundável de 4753,0 ha para a inundação histórica, valor superior em cerca de $30 \%$ à área inundável correspondente à inundação actual (3612,5 ha). Este facto ilustra as profundas alteraçôes no canal de escoamento do Rio Arunca, especialmente no sector Soure-Pombal, com influência no sector a montante. No sector a montante de Pombal o limite da inundação histórica é menos coincidente com o limite da inundação actual, o que se deve em parte à menor planura do leito maior e a obras de alargamento e aprofundamento do leito menor, levando a uma diferenciação mais nítida entre os limites dos dois tipos de inundação. A diferença entre as duas áreas inundáveis verifica-se nos três maiores cursos de água deste sector - o rio Arunca, o rio Cabrunca e a ribeira de Valmar. No sector de Soure-Pombal as diferenças de representação das áreas inundáveis podem ser explicadas pelo levantamento topográfico e aterro em áreas limítrofes ao rio Arunca, não descriminando contudo se nos sectores comuns há um aumento de altura da coluna de água ou um tempo de permanência superior. A jusante de Soure observa-se uma coincidência entre os limites das inundaçóes actual e histórica traduzindo uma menor antropizaçáo das margens e reflectindo a amplitude do plaino aluvial e a influência regressiva das cheias no Rio Mondego. Relativamente ao número de pontos críticos de escoamento, o sector que apresenta maior número de PCE é o sector entre Soure e Pombal com 130 dos 253 identificados (51\% do total), que corresponde igualmente ao sector de mais antropizado. 
Tabela 4 - Área inundável e PCE por sector do rio Arunca.

\begin{tabular}{lccc}
\hline Sector & Inundação histórica (ha) & Inundação actual (ha) & PCE \\
\hline A jusante de Soure & 1724,3 & 1705,9 & 32 \\
\hline Entre Soure e Pombal & 1929,8 & 1376,2 & 130 \\
\hline A montante de Pombal & 1098,9 & 530,4 & 91 \\
\hline Total & 4753,0 & 3612,5 & 253 \\
\hline
\end{tabular}

Para a maioria dos troços de validação (Tabela 5), nos quais se compararam as áreas correspondentes a inundação histórica e centenária, obtiveram-se valores de correlação superiores a 0,91, tendo-se verificado as maiores diferenças nas secçóes de Pombal e Vermoil (secçóes A e B), algo que está claramente associado à antropização, redefinição do canal e modelação morfológica da planície de inundação.

Tabela 5 - Comparação da área inundável por secção fluvial modelada.

\begin{tabular}{lccc}
\hline & $\begin{array}{c}\text { R. Hidrogeomorfológica } \\
\text { Inund. histórica (ha) }\end{array}$ & $\begin{array}{c}\text { Hidrológico-hidráulico } \\
\text { Inund. centenária (ha) }\end{array}$ & Correlação \\
\hline Secção A & 7,74 & 4,10 & ${ }^{(1)}$ \\
\hline Secção B & 122,36 & 102,79 & 0,206 \\
\hline Secçáo C & 183,49 & 193,43 & 0,919 \\
\hline Secção D & 714,25 & 706,68 & 0,957 \\
\hline
\end{tabular}

(1) Na Secção A (Vermoil), a reduzida dimensão do troço modelado impossibilitou a divisão do mesmo em vários talhôes de modo a se poder calcular a correlaçấo entre ambas as áreas inundáveis.

Nas secçóes modeladas situadas em Soure e a jusante de Soure (secçóes C e D) obtiveramse correlaçóes muito elevadas entre as áreas obtidas para a inundação histórica (método de reconstituição paleo-hidrogeomorfológica) e para a inundação centenária (método hidrológico-hidráulico).

\section{NOTAS FINAIS}

Os resultados obtidos por ambos os métodos na avaliação da área inundável na Bacia Hidrográfica do rio Arunca permitem constatar que a área susceptível de inundação é muito relevante, representando $8,6 \%$ da área total da bacia quando considerada a inundação histórica e cerca de 6,6\% para as condiçôes da inundação actual. Os processos de cheia e as inundaçóes associadas têm um elevado impacto em áreas urbanas, nomeadamente em Soure, Pombal, Sobral de Baixo e V. N. de Anços - como as principais localidades próximas do rio Arunca - mas também nos cursos de água de menor hierarquia, onde se identificaram elevado número de PCE.

Os resultados da aplicação da reconstituição paleo-hidrogeomorfológica permitiram constatar que os valores da área inundável para a cheia história, para a qual se assume um período de retorno de 100 anos, é cerca de 30\% superior aos valores das áreas para a cheia actual que traduzem os episódios mais recentes e para os quais há vivências e reconstituições pela população. As diferenças encontradas entre as áreas inundáveis para a cheia histórica e para a cheia actual são maiores no sector entre Soure e Pombal, assim como no sector a 
montante. As razóes parecem depender das intervençôes hidráulicas e das modificaçôes morfológicas das margens. A jusante de Soure verifica-se uma elevada correlação entre a projecção da área inundável associada à cheia histórica e à cheia actual, reflectindo a amplitude do plaino aluvial e as condiçóes de refluxo das cheias no rio Mondego.

O processo de validação hidrológica-hidráulica utilizando o software HEC-RAS permitiu comprovar a fiabilidade da reconstituição paleo-hidrogeomorfológica para as áreas inundáveis da cheia histórica. A validação permitiu ainda comprovar que o período de retorno de 100 anos assumido estava de acordo com as condiçóes de fluxo e a geometria do canal, dado que o modelo hidrológico-hidráulico foi aferido para as condiçóes da cheia centenária. $\mathrm{O}$ modelo unidimensional, em regime constante, utilizado na validação fez igualmente ressaltar que as condiçôes de menor ajuste entre a cheia centenária e a cheia histórica se encontram nas áreas objecto de importante antropização, com alteração do canal de escoamento ou modelação topográfica. Este mesmo resultado tinha anteriormente sido realçado pela discrepância entre as áreas da cheia histórica e da cheia actual. Em síntese, é realçada a importância de se desenvolver uma análise das áreas inundáveis na bacia do Rio Arunca, através da complementaridade entre métodos hidrogeomorfológicos e hidrológico-hidráulicos.

\section{REFERÊNCIAS BIBLIOGRÁFICAS}

Almeida A. C., Soares, A. F., Cunha, L. \& Marques, J. F. 1990, 'Proémio ao Estudo do Baixo Mondego', Biblos, vol. LXVI, Faculdade de Letras da Universidade de Coimbra, pp. 17-47.

Ballais, J. L., Garry, G. \& Masson, M. 2005, 'Contribution de l'hydrgéomorphologie à l'évaluation du risque d'inondation: le cas du Midi méditerranéen français', Comptes Rendus Geoscience, no. 337, pp. 1120-1130.

DGADR 1986, Escoamentos até 1984/85 - Portugal Continental. Direcção-Geral dos Recursos e Aproveitamentos Hidráulicos.

Díez-Herrero, A., Laín-Huerta, L. \& Llorente-Isidro, M. 2008, Mapas de peligrosidad por avenidas e inundaciones - Guía metodológica para su elaboración. Serie Riesgos Geológicos /Geotecnia, no. 1, Instituto Geológico Y Minero de España.

HEC 2002, HEC-RAS, River Analysis System - User's Manual. Hydraulic Reference Manual. Hydrologic Engineering Center - US Army Corps of Engineers.

IGEOE 2001, 2002, 2003, Carta Militar de Portugal (1:25 000), Série M888, folha 239, 240, 249, 250, 251, 262, 263, 273, 274, 285 e 286, Instituto Geográfico do Exército.

INAG 2002, Plano de Bacia Hidrográfica do Rio Mondego, Instituto da Água.

INAG 2007, Breve Caracterização das Cheias do Outono de 2006, Direcção dos Serviços de Recursos Hídricos, Instituto da Água.

Lastra, J., Fernández, E., Díez-Herrero, A. \& Marquínez, J. 2008, 'Flood hazard delineation combining geomorphological and hydrological methods: an example in the Northern Iberian Peninsula', Natural Hazards, no. 45 , pp. $277-293$.

Masson, M. et al. 1996, Cartographie des zones inondables. Approche hydro-géomorphologique. Paris La Défense, Les Editions Villes et Territoires.

Soares, A. M. S. 1971, A freguesia de Soure no periodo de 1725-1764, Tese de licenciatura em História apresentada à Faculdade de Letras da Universidade de Coimbra, Coimbra. 